IZA DP No. 6578

The Wage Premium of Foreign Education:

New Evidence from Australia

Gavin Chan

Christopher Heaton

Massimiliano Tani

May 2012 


\title{
The Wage Premium of Foreign Education: New Evidence from Australia
}

\author{
Gavin Chan \\ Macquarie University \\ Christopher Heaton \\ Macquarie University \\ Massimiliano Tani \\ Macquarie University \\ and IZA
}

Discussion Paper No. 6578

May 2012

IZA

P.O. Box 7240

53072 Bonn

Germany

Phone: +49-228-3894-0

Fax: +49-228-3894-180

E-mail: iza@iza.org

\begin{abstract}
Any opinions expressed here are those of the author(s) and not those of IZA. Research published in this series may include views on policy, but the institute itself takes no institutional policy positions.

The Institute for the Study of Labor (IZA) in Bonn is a local and virtual international research center and a place of communication between science, politics and business. IZA is an independent nonprofit organization supported by Deutsche Post Foundation. The center is associated with the University of Bonn and offers a stimulating research environment through its international network, workshops and conferences, data service, project support, research visits and doctoral program. IZA engages in (i) original and internationally competitive research in all fields of labor economics, (ii) development of policy concepts, and (iii) dissemination of research results and concepts to the interested public.
\end{abstract}

IZA Discussion Papers often represent preliminary work and are circulated to encourage discussion. Citation of such a paper should account for its provisional character. A revised version may be available directly from the author. 


\section{ABSTRACT \\ The Wage Premium of Foreign Education: New Evidence from Australia}

We study whether Australian employers recognise immigrants' education acquired abroad, and if so how. Using data from the Longitudinal Surveys of Immigrants in Australia, we apply interval regression to model migrant hourly earnings. We find substantially higher returns from human capital obtained in Australia and other OECD countries compared with nonOECD countries. These results suggest that the transfer of human capital acquired abroad is mediated by the country in which it was acquired, as found for Israel (Friedberg (2000) and the US (Bratsberg and Ragan (2002)). The results also suggest that immigrants from nonOECD countries are the ones who can gain the most from obtaining further education in Australia, and that targeted rather than generic policies in this area could reduce the extent of the education-occupation mismatch amongst immigrants.

JEL Classification: $\quad \mathrm{C} 34, \mathrm{~J} 24, \mathrm{~J} 61$

Keywords: immigration, education, economic assimilation

Corresponding author:

Christopher Heaton

Department of Economics

Macquarie University

North Ryde, NSW 2109

Australia

E-mail: chris.heaton@mq.edu.au 


\section{Introduction}

Since the end of the White Australia Policy, the aim of immigration policy in Australia has progressively shifted from raising the country’s population stock to the selection of immigrants with skills that can be immediately applied in the domestic labour market. The selection mechanism relies on a score set annually, with points given to a combination of individual characteristics which include age, language skills, work experience and educational level, and Australian employers’ needs summarised in a list of occupations in high demand (the "Priority Occupation List”). No points are awarded on where work experience or education was acquired, aside from Australia.

For much of the period prior to the early 2000s, there was limited discussion on the effectiveness of these selection criteria, as a number of immigrants' labour market outcomes, like average participation and employment rates, pointed towards relatively successful economic assimilation with native workers.

More recent labour market analyses however have documented that immigrants to Australia and to other developed countries face a higher incidence of education-occupation mismatch than native workers (e.g. Kler et al. (2007)). This not only contributes to income inequality between foreign and native workers, but affects national productivity through the under-use of foreign-born human capital. Among the causes of such mismatch, the literature has pointed to institutional factors in the countries of origin (e.g. pre-migration mismatch as in Piracha, Tani, Vadean (2010)), in those of destination (e.g outright discrimination in the labour market as in Battu and Sloane (2004)), and the imperfect international transferability of human capital (Chiswick and Miller (2009)). We combine the latter two possible explanations by studying whether Australian employers recognise education acquired abroad, and if so how. In particular, we investigate the determinants of immigrants' wages according to whether they acquired their formal education in an OECD (Organisation for Economic Cooperation 
and Development) or non-OECD country of origin using immigration data from the Longitudinal Surveys of Immigrants to Australia. The choice of the OECD as a country grouping reflects the member states’ medium- and high- level of income and development, and a broadly common set of economic policies and approaches. It also reflects a common approach in the (limited) existing literature on this topic (e.g. Friedberg (2000), Bratsberg and Ragan (2002)).

The results show that the human capital of immigrants educated in another OECD country enjoys a higher premium than if obtained from non-OECD countries. As a result the transfer of human capital acquired abroad filters through the country in which it was acquired, and Australian employers appear to recognize this through the wage paid. This result also suggests that immigrants from non-OECD countries are the ones who can gain the most from obtaining further education in Australia, and that targeted rather than generic policies in this area could be fruitful to reduce the extent of the education-occupation mismatch amongst immigrants.

The rest of the paper is organised as follows. Section 2 briefly reviews the relevant literature. Section 3 describes the data and presents the empirical approach undertaken. Section 4 discusses the results while Section 5 provides some concluding remarks.

\section{Literature Review}

There is a substantial literature analysing the imperfect transferability of human capital across countries as an impediment to labour market success for recent immigrants. This research posits that differences in language, culture, education systems, and labour market institutions across countries affect negatively the productivity and earnings of migrant workers. Only by accumulating skills and knowledge specific to the host country through time spent there, by 
either working or studying, can a migrant could overcome his/her wage 'discount' (e.g. Chiswick (1978), Borjas (1987)).

Although this conclusion has long been verified, the hypothesis that the quality and degree of compatibility of foreign human capital with the host country's labour market requirements depends on where exactly education was acquired has received attention only recently (e.g. Friedberg (2000)). Given that immigrants have different combinations of foreign and domestic human capital, Friedberg argues that standard earnings functions treating them as homogenous variables yield biased estimates. After addressing the identification problem about where education is acquired, her study on immigrants in Israel confirms that education in the host country earns the highest rate of return. Hence several years of formal education in Israel do eliminate a large portion of the gap between foreign and domestic returns to human capital. Furthermore, she also finds that amongst foreign sources schooling from Western countries obtains the highest rewards. These results also apply to work experience. Subsequent analyses applied to the US (e.g. Bratsberg and Ragan (2002)) and Australia (e.g. Chiswick, Lee and Miller (2005), Parasnis, Fuasten and Cheo (2008)) largely support these conclusions even when countries of origin are no longer grouped by average income level (as in Bratsberg and Ragan (2002)), but by cultural and linguistic distance (as in Chiswick and Miller (2005)).

Interestingly, when the level of economic development between home and host countries and the cultural distance are very similar, immigrants seem to experience what Chiswick and Miller (2012) call ‘negative assimilation’. This consists in initially high earnings followed by negative earnings growth. This puzzling result is interpreted as the result of workers from a certain sub-set of home countries (typically English-speaking high-income ones) receiving an initial high wage offer pre-migration to compensate for the fixed costs of moving to Australia. 
As time progresses employers remunerate only the human capital component of the immigrant, not the cost of moving, with consequent lower future earnings growth.

Our study complements the existing work on the economic assimilation of Australia's immigrants by distinguishing the countries where education was acquired, using the OECD as a way of grouping vastly heterogeneous countries of origin. By so doing we maintain the approach of earlier work in this area and complement the investigations of Chiswick and Miller (2009, 2012) based on linguistic distance.

Within the literature on the international transferability of human capital, many studies use the years of education as a measure of human capital. This approach is subject to criticism as years of schooling are a less informative signal of productivity compared with using variables for program completion because it fails to account for dropouts and those who spend more time in education due to failing courses (e.g. Ferrer and Riddell (2008)). As a result, we use the level of education as a measure of human capital in the empirical analysis that follows.

\section{Data}

The data used in this study comes from the Longitudinal Surveys of Immigrants to Australian (LSIA). Each survey contains information on a cohort of immigrants aged 15 years or over who received their visas overseas and have arrived in Australia in the prior six months. The surveys are intended to document their initial experiences in Australia after entry, and provide data on immigrants' characteristics and their labour market and housing experience, as well as their expectations and thoughts on the settlement process. The first survey, LSIA1, collects data on immigrants entering Australia between September 1993 and August 1995. Face to face interviews were conducted over the course of 3.5 years after immigration with the first, second and third interviews occurring on average 5, 17 and 41 months after arrival. A total of 5,192 primary applicants were surveyed in the first wave of interviews in LSIA1. 
LSIA2 had a sample size of 3,192 primary applicants in the first interview. These immigrants entered Australia between September 1999 and August 2000. A total of two interviews were conducted in LSIA2 approximately 5 and 17 months after migration.

Table 1: Sample characteristics

\begin{tabular}{|lll|}
\hline & Cohort 1 & Cohort 2 \\
\hline Visa Category & $42 \%$ & $49 \%$ \\
Family Preferential & $14 \%$ & $9 \%$ \\
Skilled Australian Linked & $10 \%$ & $11 \%$ \\
Business/Employer Nominated & $16 \%$ & $12 \%$ \\
Independent & $16 \%$ & $17 \%$ \\
Humanitarian & & \\
Age & $14 \%$ & $15 \%$ \\
$15-24$ & $47 \%$ & $39 \%$ \\
$25-34$ & $23 \%$ & $24 \%$ \\
$35-44$ & $12 \%$ & $14 \%$ \\
$45-64$ & $3 \%$ & $6 \%$ \\
65 and over & & \\
Labour Force Status & $63 \%$ & $82 \%$ \\
Employed & $37 \%$ & $18 \%$ \\
Unemployed & & \\
Former Home Country & $14 \%$ & $9 \%$ \\
English speaking OECD & $12 \%$ & $12 \%$ \\
Non-English speaking OECD & $38 \%$ & $42 \%$ \\
South, East and South East Asia & $7 \%$ & $7 \%$ \\
Africa & $7 \% \%$ & $25 \%$ \\
Other & & \\
Education & $16 \%$ & $17 \%$ \\
Postgraduate & $22 \%$ & $21 \%$ \\
Bachelor or Equivalent & $28 \%$ & $26 \%$ \\
Trade/Certificate/Diploma & $15 \%$ & $17 \%$ \\
Completed High School & $18 \%$ & $18 \%$ \\
Did not complete High School & & \\
Australian Qualifications & $4 \%$ & $5 \%$ \\
Yes & $96 \%$ & $95 \%$ \\
No & & \\
Interview in English & $59 \%$ & $62 \%$ \\
Yes & $41 \%$ & $38 \%$ \\
No & & \\
\hline & & \\
\hline
\end{tabular}

We restrict our attention to primary applicants because tied movers such as spouses or children are also classified under the same visa but do not need to fulfil the visa's requirements. We look specifically at those who indicated that they were currently employed and earning positive income at the time of interview. After removing observations with 
missing values on key variables, a sample size of 8,674 remained for the pooled analysis. Table 1 shows the descriptive statistics for immigrants in the first interview of each LSIA.

The majority of primary applicants in both cohorts were in the primary working age of 25 to 44 years old and highly educated, reflecting adherence to the main selection criteria for permanent resettlement to Australia. The Family Stream constitutes the largest component of the Permanent Migration Program with over $40 \%$ of migrants in this visa class in both surveys. Table 1 indicates that only a small proportion of migrants held Australian qualifications initially, but this dramatically increases in subsequent waves of each cohort. For example, by the third interview of the first cohort, $27 \%$ of migrants had completed Australian qualifications compared with just $4 \%$ in the first interview.

Most immigrants were interviewed in English, particularly those in LSIA2 who entered Australia under stricter selection criteria were introduced since the mid-1990s, confirming their high level of language skills.

\section{Methodology}

The methodological basis for this study is the Mincerian earnings function (Mincer (1974)) that is used almost universally in the literature. Specifically, our empirical model is

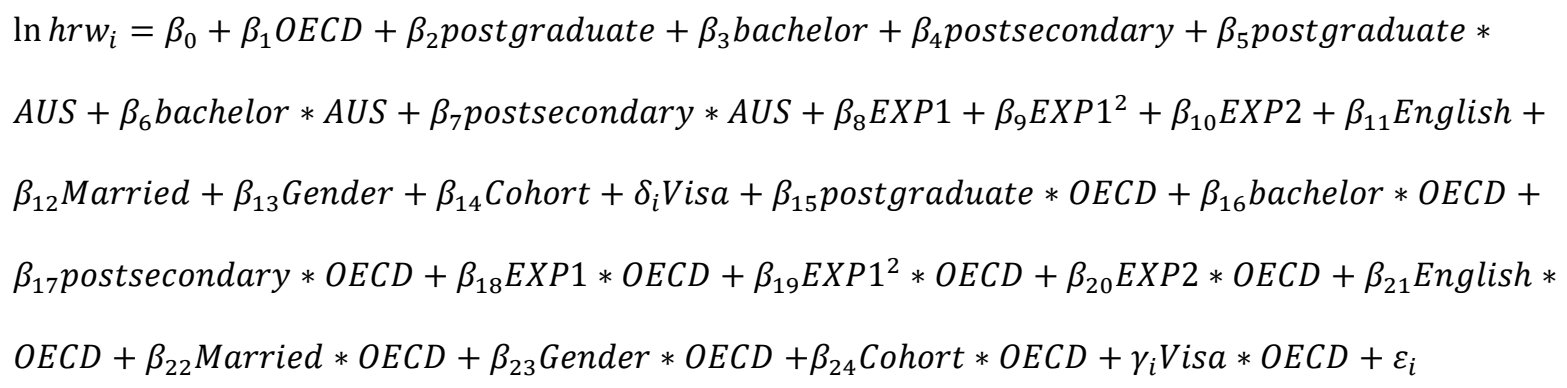

where

$\ln h r w_{-} i=$ the hourly wage rate of the individual; 
EXP1 = years of work experience in the home country;

EXP2 = years of work experience in Australia.

$O E C D=1$ if the immigrant is from an OECD country, 0 otherwise;

AUS = 1 if the highest qualification was obtained in Australia, 0 otherwise;

Vis $a$ a vector of four dummy variables representing visa categories with the SkilledIndependent class as the base;

Cohort $=1$ if the immigrant is in the second cohort;

English = 1 if the immigrant has good English skills (as indicated by the interview being conducted in English), 0 otherwise;

Married $=1$ if the immigrant is married, 0 otherwise;

Gender $=1$ if the immigrant is male, 0 otherwise;

Postgraduate $=1$ if the highest qualification obtained is at the postgraduate level, 0 otherwise;

Bachelor $=1$ if the highest qualification obtained is at the bachelor level or equivalent, 0 otherwise;

Postsecondary = 1 if the highest qualification obtained is a trade qualification, certificate or diploma.

A practical complication in estimating Equation 1 is that, while the LSIA surveys collect data on the exact number of hours worked, the precise wage and salary details are not collected.

Rather, the survey presents respondents with a schedule of bands of wages and asks them to identify in which band their earnings lie. Consequently, for each individual, instead of observing their weekly earnings, we observe one of the twelve separate categories for their weekly earnings. The lowest category is $\$ 1$ to $\$ 57$ a week; the highest $\$ 962$ or more a week. These values are divided by the individual hours of work that an immigrant undertakes per week to obtain the lower and upper bounds of their hourly earnings. For example, the two bounds for an individual indicating an income in the first category would be $\ln \left(\frac{\$ 1}{\text { hours }_{i}}\right)$ and $\ln \left(\frac{\$ 57}{\text { hours }_{i}}\right)$. These values are denoted by $L_{i}$ and $U_{i}$ respectively for each individual. It can be 
seen that the bounds for individual i are related to the unobserved hourly earnings equation in the following way:

$$
L_{i} \leq \ln h r w_{i}^{*} \leq U_{i}
$$

A common approach to dealing with categorical earnings data of this type is to assign each individual an assumed weekly earning equal to the mid-point of the band in which their actual earnings are reported to lie. For the upper band, which is unbounded, an arbitrary convention is adopted (e.g. assigning a value equal to 1.5 times the lower bound). The earnings function (Equation (1)) with the dependent variable so defined, may then be estimated using Ordinary Least Squares (OLS) or related methods. Examples of this approach include Hartog (1985), Hartog (1986), Preston (1997), Kler (2005) and Kifle (2009). However, Stewart (1983) has proved that this approach yields inconsistent estimates. In this paper, we adopt a maximum likelihood approach that explicitly considers the imperfect observability of the dependent variable. This model is referred to as an Interval Regression by Wooldridge (2001). Standard arguments (see, e.g. Greene (2003)) establish the consistency and asymptotic normality of this estimator.

Under the assumption that the disturbance term in the Mincer equation is normally distributed with variance $\sigma^{2}$ we can state the probability of observing an individual with their indicated income category conditional on the explanatory variables in the sample as:

$$
\begin{aligned}
P\left[L_{i} \leq \ln h r w_{i}^{*} \leq U_{i}\right] & =P\left[L_{i}-x_{i}^{\prime} \beta \leq e_{i} \leq U_{i}-x_{i}^{\prime} \beta\right] \\
& =\Phi\left[\frac{L_{i}-x_{i}^{\prime} \beta}{\sigma}\right]-\Phi\left[\frac{U_{i}-x_{i}^{\prime} \beta}{\sigma}\right]
\end{aligned}
$$


where $\Phi($.$) is the standard normal CDF, x_{i}$ is the vector of explanatory variables and $\beta$ is the vector of parameters. Therefore, the log probability of observing the given sample is given by the log likelihood function:

$$
\ln \mathcal{L}=\sum_{i=1}^{N} \ln \left[\Phi\left(\frac{L_{i}-x^{\prime} \beta}{\sigma}\right)\right]-\ln \left[\Phi\left(\frac{U_{i}-x^{\prime}{ }_{i} \beta}{\sigma}\right)\right]
$$

The interval regression implemented here is similar in structure to the ordered probit model. Indeed, the likelihood functions are identical. The difference between the two models is that, for the ordered probit model, the error variance is assumed to be 1 and the bounds $L_{-} \mu_{i}$ and $U_{-} \mu_{i}$ are estimated. In the interval regression model, the bounds $L_{-} \mu_{i}$ and $U_{-} \mu_{i}$ are known and the error variance is estimated.

\section{Results}

Table 3.1 presents the pooled interval regression results for immigrants across all waves and both surveys. The middle column contains the estimated coefficients for non-OECD migrants. They represent the percentage change in hourly earnings resulting from a unit change in the associated variable. The right column contains the coefficients for the applicable variables interacted with the $O E C D$ variable, which represent the additional percentage effects of those variables on hourly earnings for OECD migrants. The Likelihood ratio statistic for the regression indicates that the independent variables are jointly significant in explaining hourly wages and the variance of the error is approximately 0.5 . The estimated coefficients for education, work experience and visa categories are highly significantly different from zero. The negative coefficient estimate for OECD indicates that the intercept for immigrants from these countries is lower than that for non-OECD migrants. However, the effects of the different slope terms and dummy variables for OECD migrants indicate that they perform 
substantially better than non-OECD migrants. For example, the model predicts that a typical Independent-Skilled immigrant in the second cohort with a bachelor's degree, 3 years of premigration work experience and 1 year of work experience in Australia earns \$17.14 per hour if the human capital and migrant were from a non-OECD country and \$21.46 if from an OECD country. The coefficient estimates on pre-migration work experience for migrants from non-OECD countries experience suggest that pre-migration work experience raises productivity in Australia for up to 20 years and then begins to taper off. The average level of work experience for non-OECD migrants before migration in the sample is 13 years indicating that the typical immigrant receives a modest mark-up of $4.5 \%$ in earnings for this. Furthermore, these variables are on the margin of statistical significance indicating that the evidence for the effect of pre migration experience and earnings in the Australian labour market is weak. The coefficients for the OECD interaction terms for pre-migration work experience indicate the additional mark up of pre-migration work experience for those from OECD countries. These effects are substantially larger than for migrants from non-OECD countries, suggesting that there is a higher value placed on OECD work experience in the labour market. Earnings increase for work experience up to approximately 25 years and, at the average level of experience for migrants from OECD countries of 13 years, a migrant receives a wage premium of almost $28 \%$. The estimates for these coefficients are also highly statistically significant. These results demonstrate that work experience is rewarded differently depending on where it is obtained and are consistent with the idea that human capital is more transferable between more similar countries.

The estimated coefficients for Australian work experience indicate that local experience increases hourly wages by $4.3 \%{ }^{11}$ per year for the base group and $7.5 \%{ }^{22}$ for migrants from

1 Coefficient for EXP2 refers to days since migration and hence yearly returns are calculated as $0.00012 \times 365=0.043$ for non-OECD migrants 
OECD countries shortly after arrival. Unfortunately, this variable is imperfectly measured and combines the effects of actual labour market experience in Australia and passive accumulation of general skills and knowledge of the local culture, language, networking etc. while unemployed. Due to the low response rate in the surveys from immigrants regarding

Table 2. Interval Regression of Weekly Earnings of Migrants in LSIA1 and LSIA2

\begin{tabular}{|l|l|l|}
\hline \multicolumn{2}{|l|}{ Variable } & \multicolumn{2}{l|}{$\begin{array}{l}\text { OECD } \\
\text { Interaction }\end{array}$} \\
\hline Postgraduate & $0.313^{* * * 3}$ & -0.025 \\
& $(0.027)$ & $(0.039)$ \\
\hline Bachelor & $0.141^{* * *}$ & $0.159^{* * *}$ \\
& $(0.023)$ & $(0.037)$ \\
\hline Trade/Diploma/Certificate & $0.077^{* * *}$ & -0.030 \\
& $(0.021)$ & $(0.031)$ \\
\hline Australian Postgraduate & 0.013 & \\
\hline Australian Bachelor & $(0.031)$ & \\
\hline Australian & $0.061^{* *}$ & \\
Trade/Diploma/Cert & $(0.028)$ & \\
\hline Home Work Experience & $-0.054^{*}$ & \\
& $(0.029)$ & \\
\hline Home Work Experience & $0.005^{*}$ & $0.0276^{* * *}$ \\
& $(0.0028)$ & $(0.0052)$ \\
\hline Australian Work Experience & $-0.00012^{*}$ & $-0.00075^{* * *}$ \\
& $(0.000073)$ & $(0.00014)$ \\
\hline English Proficiency & $0.00012^{* * *}$ & $0.000087^{* * *}$ \\
& $(0.000031)$ \\
\hline Marital Status & $0.186^{* * *}$ & 0.031 \\
& $(0.0197)$ & $(0.047)$ \\
\hline Gender & $0.084^{* * *}$ & $-0.075^{* * *}$ \\
& $(0.016)$ & $(0.027)$ \\
\hline Cohort & $0.051^{* * *}$ & 0.025 \\
& $(0.016)$ & $(0.026)$ \\
\hline Family Visa & $0.196^{* * *}$ & $0.051^{*}$ \\
& $(0.017)$ & $(0.028)$ \\
\hline Skilled Australian Linked & $-0.272^{* * *}$ & $0.107^{* * *}$ \\
Visa & $(0.021)$ & $(0.033)$ \\
\hline Business/Employer & $-0.185^{* * *}$ & $0.060^{* * *}$ \\
Nominated & $(0.021)$ & $(0.019)$ \\
\hline & -0.035 & $0.284^{* * *}$ \\
& $(0.027)$ & $(0.043)$ \\
\hline
\end{tabular}

2 Returns to days since migration for OECD migrants is calculated as $(0.00012+0.00008) \times 365=0.075$ 


\begin{tabular}{|l|l|l|}
\hline Refugee Visa & $\begin{array}{l}-0.263^{* * *} \\
(0.028)\end{array}$ & $\begin{array}{l}-0.219 \\
(0.168)\end{array}$ \\
\hline OECD & & $-0.150^{* *}$ \\
& & $(0.072)$ \\
\hline Constant & $2.210^{* * *}$ & \\
& $(0.039)$ & \\
\hline Note: Standard errors in parenthesis. \\
$* * *$ Statistically significant at the 1\% level \\
$* *$ Statistically significant at the 5\% level \\
* Statistically significant at the 10\% level \\
Observations = 8674; $\hat{\sigma}^{2}=0.49877 ;$ LR statistic $=2447.81$ \\
\hline
\end{tabular}

time unemployed while in Australia, direct comparisons between the value of pre migration experience and Australian experience cannot be made. However, the data that do exist suggest that the average period of unemployment is short. If this is representative of all migrants, then it suggests that the majority of the increase in earnings from years in Australia can be attributed to actual labour market experience. With the return from the first year of pre-migration experience at $0.5 \%$ for non-OECD migrants and 3.2\% for OECD migrants, it implies the Australian labour market strongly favours domestic experience over work experience from abroad. The estimated coefficient of the OECD interaction term for the Australian work experience variable indicates that migrants from OECD countries make a faster transition into Australia and is in accordance with the findings of different assimilation rates by region of origin in Bloom, Grenier and Gunderson (1995). Similarities in language, labour market structures and culture could be facilitating the adjustment and faster earnings growth in the initial period after migration for OECD migrants.

Educational attainment is represented by three dummy variables; postgraduate level, bachelor or equivalent and post-secondary which includes trade, certificate or diploma qualifications.. High school graduates and below is the omitted category and this forms the base group. The pooled interval regression reveals that postgraduate education raises hourly earnings by $31.3 \%$ 
over the base group. Bachelor level and post-secondary qualifications are similarly important, increasing earnings by $14.2 \%$ and $7.7 \%$ respectively. LSIA data not presented in this paper indicate that migrants with higher education have a general tendency to also work longer hours on average, meaning that the gap in total weekly earnings would be more pronounced at each education level. Overall, these results demonstrate that the level of education is an important determinant of immigrant earnings.

The education variables are interacted with the OECD dummy variables to investigate the differences in returns to education across countries in the labour market. The results show that, amongst immigrants with bachelor degrees, those from OECD countries enjoy an hourly wage premium of $15.9 \%$ compared to those with bachelor degrees from non-OECD countries. However we find no evidence that postgraduate and postsecondary educational qualifications from OECD countries lead to higher hourly wages than the same level of education from non-OECD countries. A similar pattern is observed for Australian qualifications. At the bachelor level, there is evidence that Australian degrees lead to a $6.1 \%$ hourly wage premium over non-OECD non-Australian bachelor degrees. At the postgraduate and postsecondary levels, there is no strong evidence that Australian qualifications lead to a premium over nonOECD non-Australian qualifications. The implication of these findings is that the country in which qualifications are obtained is a significant factor consideration in the returns to education. Education from non-OECD countries may be viewed as lower quality or may be less compatible with the needs of the Australian labour market whereas education from Australia and other OECD countries appear to be more valued. 
The pooled analysis shows significant positive effects from English proficiency increasing hourly wages by $18.6 \%$. These results are broadly similar to estimates in other analyses on immigrants in Australia and the USA (e.g. Chiswick and Miller (1995; 2004; 2009) and Bratsberg and Ragan (2002)). The high wage premium from English language proficiency is remarkable. Indeed, it is greater than that available from a non-OECD bachelor degree.

The results indicate that married immigrants have hourly earnings that are $8.4 \%$ higher than those of non-married immigrants, but this is only applicable to those from non-OECD countries. Males are found to have hourly wages approximately $5.1 \%$ higher than equivalently qualified females. The regression identifies the second cohort of immigrants as having much higher earnings with an estimated 19.6\% advantage over the first cohort with those from OECD countries receiving a further 5.1\% above this. The migrants in the Skilled Stream of the second cohort entered Australia under stronger requirements regarding education, experience, age and language skills. Moreover, access to social security benefits were generally withheld to all migrants arriving after the 1996 apart from those under the Humanitarian Stream. These results suggest that the policy changes were effective in deterring migrants who were less confident or motivated and thus not likely perform well in the labour market.

The Australian government annually adjusts the intake of migrants from different visa categories in order to achieve specific goals and the focus in recent years has been on the economic stream. We included dummy variables for visa categories to investigate the differences in labour market performance across the different types of applicants. The base group includes all holders of Independent visas and amongst non-OECD migrants, only those 
in the Business Skills/Employer Nominated categories had earnings comparable to that group. Preferential Family and Humanitarian visa holders performed the worst with hourly earnings estimated at $27.2 \%$ and $26.3 \%$ less than Independent migrants. Concessional Family migrants who are required to meet some skills requirements fared better experiencing a smaller earnings deficit of $18.5 \%$. The estimates are highly statistically significant and reveal that migrants undergoing more stringent assessments of abilities enjoy greater success in the labour market. As the model controls for many of the factors included in the points test, the results suggest that there are differences in unobservable characteristics of people applying for certain visas with those prepared to show evidence of their skills also possessing qualities that increase their earning capacity e.g. stronger work ethic, self confidence, perseverance etc.

The visa categories are also interacted with the OECD dummy variable. This illustrates any differences in earnings for holders of each visa category depending on their country of origin. Interestingly, migrants from OECD countries experience higher earnings compared to their counterparts from non-OECD countries in every visa category except for those from the Humanitarian Stream. However, since there are almost no refugees from OECD countries this result is of little economic significance. The results reveal that Business Skills/Employer Nominated migrants from OECD countries are the most successful group in the migration program with earnings greatly exceeding that of Independent migrants. The model suggests that the hourly earnings of this group is $28.4 \%$ higher and this may be a result of the closer ties between OECD countries facilitating the success of businesses or more similar economic and political structures with Australia making migrants from these countries better able to adapt their entrepreneurial skills after migration. The earnings deficit reported for migrants in the Preferential Family and Concessional Family categories is reduced to $16.5 \%$ and $12.5 \%$ respectively for those from OECD countries. The general pattern of better economic 
outcomes for those undergoing stricter skills assessments is preserved for migrants from OECD countries.

\section{Conclusions}

These results show that migrants from OECD countries are generally more productive than migrants from non-OECD countries in Australia. Similarities in level of economic development, approaches to education, economic policy and infrastructure between members may be the reason for migrants educated in another OECD country to outperform similarly migrants from non-OECD countries. This finding supports those of Friedberg (2000) and Bratsberg and Ragan (2002), and highlights that a targeted policy intervention towards nonOECD educated migrants might contribute to enhance their labour market performance in Australia.. As the benefits of an efficient use of human resources affect the entire Australian community through improved productivity and not only the individuals involved through higher wages, our results suggest the existence of a space for future policy action. Future work on this topic will enable to identify the exact form in which possible support to nonOECD educated migrants in Australia can be implemented.

\section{References}

Battu, H. and Sloane, P. J. (2004), 'Over-education and ethnic minorities in Britain' The Manchester School 72, 535-559.

Bloom, D.E., G. Grenier and M. Gunderson. (1995), 'The changing labour market position of Canadian immigrants', The Canadian Journal of Economics 28, 987-1005.

Borjas, G. J. (1987), 'Immigrants, minorities, and labor market competition’ Industrial and Labor Relations 40, 382-292.

Bratsberg, B. and Ragan J.F. (2002), 'The Impact of Host-Country Schooling on Earnings: A Study of Male Immigrants in the United States', Journal of Human Resources 37, 63-105.

Chiswick, B. (1978), 'The effect of Americanization on the earnings of foreign-born men', Journal of Political Economy 86, 897-921. 
Chiswick, B. (1986), 'Is the New Immigration Less Skilled Than the Old?',.Journal of Labor Economics 4, 168-192.

Chiswick, B. R. and Miller, P. W. (1985), 'Immigrant generation and income in Australia' Economic Record 61, 540-553.

Chiswick, B.,R and Miller, P.W. (2004), 'The Determinants of Post Immigration Investments in Education.' Economics or Education Review 13 163-177.

Chiswick, B.R. and P.W. Miller (2006). Language Skills and Immigrant Adjustment: What Immigration Policy Can Do! In: Deborah Cobb-Clark and Siew-Ean Khoo (eds.), Public Policy and Immigrant Settlement, Cheltenham: Edward Elgar Publishing, 121-148.

Chiswick, B. R. and Miller, P. W. (2009), 'The international transferability of immigrants' human capital', Economics and Education Review 28, 162-169.

Chiswick, B.R and Miller, P.W. (2012), 'Negative and Positive Assimilation, Skill transferability and Linguistic Distance', Journal of Human Capital 6, 35-55.

Chiswick, B. R., Lee, L.Y. and Miller, P.W. (2005), 'Immigrant Earnings: A Longitudinal Analysis’, Discussion Paper Series IZA DP no.1750.

Ferrer, A. and Riddell W.C. (2008), 'Education, Credentials and Immigrant Earnings', Canadian Journal of Economics 41 186-216.

Friedberg, R. (2000) 'You can't take it with you? Immigrant assimilation and the portability of human capital', Journal of Labor Economics 18 221-251.

Greene, W. H. (2003), Econometric Analysis, $5^{\text {th }}$ edition, Prentice-Hall.

Hartog, J. (1985), 'Earnings functions: Testing for the demand side’, Economics Letters 19, 281-285.

Hartog, J. (1986), ‘Allocation and the earnings function’ Empirical Economics 11, 97-110.

Kifle, T. (2009), 'The effect of immigration on the earnings of native-born workers:

Evidence from Australia’ The Journal of Socio-Economics 38, 350-356.

Kler, P. (2005), 'Graduate overeducation in Australia: A comparison of the mean and objective methods’ Education Economics 13, 47-72.

Kler, P. (2007). A panel data investigation into overeducation among tertiary educated Australian immigrants. Journal of Economic Studies, 34(3) 179-193.

Mincer, J. (1974), ‘Schooling, Experience and Earnings’ New York: NBER.

Parasnis. J. Fausten, D. and Cheo, R. (2008), 'Do Australian qualifications help? The effect of host country qualification on migrant participation and unemployment'. Economic Record 84, 131-140. 
Piracha, M., Tani, M., and Vadean, F. (2010). "Immigrant over- and under-education: The role of home country labour market experience”, IZA, Discussion Paper No. 5302.

Preston, H. (1997), 'Where are we now with human capital theory in Australia?', Economic Record 73, 51-78.

Schoeni, Robert.F.(1997), 'New Evidence on the Economic Progress of Foreign-Born Men in the 1970s and 1980s', The Journal of Human Resources 32, 683-740.

Stewart, M. (1983), 'On Least Squares Estimation when the Dependent Variable is Grouped', Review of Economic Studies 50, 737-753.

Wooldridge, J. M. (2001), Econometric Analysis of Cross-Section and Panel Data, Cambridge: MIT Press. 